\title{
Interdecadal Changes of Cyclone Activities in the North of East Asia during Boreal Spring
}

\author{
Xueyan Yang ${ }^{1, *}$, Shiqi Xu ${ }^{1}$, Li Zhang ${ }^{1}$, Yulin Qin ${ }^{2}$ and Mengting Pan $^{3}$ \\ ${ }^{1}$ Climate Center of Jilin Province, Changchun 130062, China \\ ${ }^{2}$ Meteorological Observatory of Jilin Province, Changchun 130062, China \\ ${ }^{3}$ Collaborative Innovation Center on Forecast and Evaluation of Meteorological Disasters, Key Laboratory of Meteorological \\ Disaster (Nanjing University of Information Science and Technology), Ministry of Education, Nanjing 210044, China \\ ${ }^{*}$ Corresponding author
}

\begin{abstract}
Based on NCEP/NCAR reanalysis data from 1961 to 2016, an objective identification algorithm was applied to identify the cyclones in the north of East Asia. In addition, the climate characteristics of the cyclone activity was investigated. The results show that the active areas of cyclones in the north of East Asia are mainly distributed in the $42.5-52.5^{\circ} \mathrm{N}$ latitudinal zone. There is an active cyclone center in the west of Mongolia and the southeastern Mongolia. Meanwhile, there are two cyclone activity centers in northeast China. The interdecadal changes of the occurrence frequency of cyclones in the north of the East Asia were significant, with relatively more cyclones from 1961 to 1978 , less cyclones from 1979 to 2003, and more cyclones from 2004 to 2016. The occurrence frequency of the cyclones in the north of East Asia from 1961 to 1999 showed a significant decreasing trend and a significant increasing trend from 2000 to 2016. Morlet wavelet analysis showed that there is a significant period of 2-3 years in the occurrence frequency of cyclones in March, April, and May during the period from 1961 to 2016. The interdecadal changes of the cyclone activities may be explained by the changes of the meridional temperature gradients in different decades.
\end{abstract}

Keywords-interdecadal change; cyclone activity; objective identification algorithm of cyclones; climate change; meridional temperature gradient

\section{INTRODUCTION}

Cyclone is an important weather system in the atmosphere. Tropical cyclone is usually accompanied by strong winds and heavy rainfall, which can cause serious disasters in the affected areas. Extratropical cyclone is often accompanied by the alternation of cold and warm air, often bringing strong winds, precipitation, and sandstorm, low temperature weather to the affected areas. In the early days, people paid more attention to the generation of cyclones, the structure of cyclones, and the weather impact they produced. Bjerknes and Solherg [1] proposed the cyclone development model. Petterssen [2] suggested the cyclone development formula that uses the local change of the $1000 \mathrm{hPa}$ vorticity to represent the development of the surface cyclone. Hoskins et al. [3] used potential vorticity to study cyclone wave development. In the mid-1980s, scientists began to notice the climate change and its possible causes of cyclone activity frequency. Serreze et al. [4] analyzed cyclone activity in the Arctic Ocean region from 1952 to 1989 and found that there are frequent cyclone activities in winter, and the strongest cyclone systems are principally found in the sea areas of Iceland and Norway. Sick-möller et al. [5] found that the number of extratropical cyclones in the North Atlantic showed a decreasing trend. McCabe et al. [6] found that the occurrence frequency of surface cyclones in the mid-latitudes of the Northern Hemisphere has a decreasing trend, while that of high-latitude cyclones has increased. Schneiderreit et al. [7] found that the number of cyclones in Iceland increased during 1958-2001. The activity area of the East Asian cyclone extends from the mainland China, north of $20^{\circ} \mathrm{N}$ to the vast sea of the western Pacific. It has a pronounced impact on the inland and offshore weather, which has attracted the attention of meteorologists. Wang et al. [8] found that during the period 1958-2001, the occurrence frequency of mid-high latitude cyclones in East Asia changed with the decreasing trend in the South and increasing trend in the North. Some previous studies have investigated the climatological characteristics of the East Asian cyclone. However, most of these studies analyzed the cyclone activities before the year 2000. There are still some questions which remain to be answered, say, the trend of the East Asian cyclone activity during boreal spring is still decreasing? What is the reason for the climate change of the cyclone activities? To answer these questions, this study uses the NCEP/NCAR reanalysis data and an objective identification method to identify the cyclones in the north of East Asia during the period from 1961 to 2016, and analyzes the interdecadal variations of the cyclone activities in the north of East Asia. It is of importance for understanding the background of climate change and the climate prediction in this region.

\section{DATA AND Methods}

\section{A. Data}

In this study, NCEP/NCAR reanalysis data are used. The data include daily sea level pressure, monthly $500 \mathrm{hPa}$ and $1000 \mathrm{hPa}$ geopotential height, wind, and temperature field data with a resolution of $2.5^{\circ} \times 2.5^{\circ}$ from 1961 to 2016 . The boreal spring refers to March, April and May of each year.

\section{B. Method for Objective Identification of Cyclones}

Many scientists have used the objective identification method to calculate the distribution characteristics of cyclones 
and anticyclones, and studied their interannual and interdecadal variations [9-16]. The objective identification methods for cyclones and anticyclones in these studies can also be used for this study. For the objective identification algorithm of cyclones, in most studies, the local minimum of sea-level pressure or the local maximum of vorticity in the lower troposphere is by and large defined as the center of an extratropical cyclone. Hoskins and Hodges [17] believed that the use of vorticity can identify smaller-scale cyclones and therefore can be applied to early-stage cyclones. Wernli and Schwierz [10] developed a numerical algorithm that searches for closed contours around the local minimum of the pressure field. Fu et al [12] used a combination of sea-level pressure field and pressure gradient to identify cyclones affecting the winter months of northern China. The scheme of Wernli and Schwierz [10] doesn't take into account the pressure gradient force and is likely to identify the local low pressure as a cyclone. However, the method of $\mathrm{Fu}$ et al. [12] recognizes some of the inverted troughs that have low pressure centers but no closed contours as cyclones. This paper takes into account these two methods comprehensively to identify cyclones more accurately. The identification scheme is as follows:

a) The sea level pressure at the center of the cyclone is lower than the sea level pressure at the surrounding eight grid points, and there are closed contours within the three grid points extending around the low pressure center;

b) The pressure value at the cyclone center is less than $1028 \mathrm{hPa}$;

c) The mean pressure gradient is greater than or equal to $0.55 \mathrm{hPa} / 100 \mathrm{~km}$ within $5 \times 5$ grids surrounding the cyclone center.

\section{FeATURES OF THE CYCLONE ACtIVITIES}

From the statistical analysis results of cyclone identification from 1961 to 2016 (Figure I), in the spring cyclones in the north of East Asia are active in the $42.5^{\circ}$ $52.5^{\circ} \mathrm{N}$ latitudinal zone and can be divided into four active areas. There is an active cyclone center in the west of Mongolia and in the southeast of Mongolia. Cyclones are also active in the eastern part of the Greater Khingan Range and the Songhuajiang-Nenjiang Plain in Northeast China. In addition, there are two cyclone activity centers which are located in the north of Heilongjiang province and from the east of Inner Mongolia to the west of Jilin province in China, respectively.

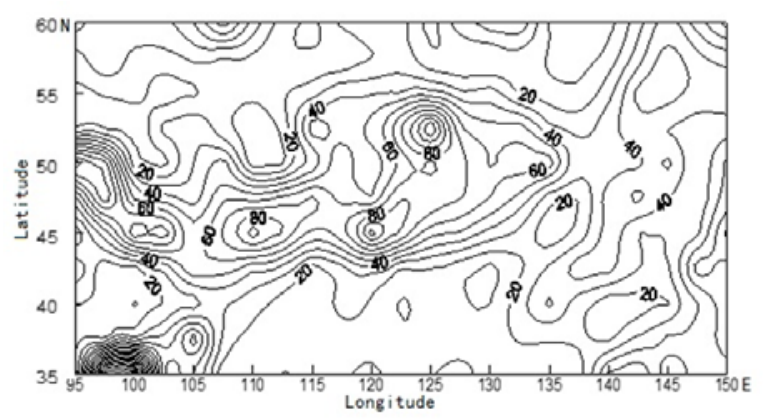

FIGURE I. DISTRIBUTION OF THE CYCLONE OCCURRENCE FREQUENCY IN THE NORTH OF EAST ASIA DURING THE SPRING OF 1961-2016

\section{CHARACTERISTICS OF CYCLONE INTENSITY IN THE NORTH OF EAST ASIA}

During the spring of 1961-2016, the average intensity of cyclones in the north of East Asia was $1001 \mathrm{hPa}$, with the strongest reaching $960.9 \mathrm{hPa}$ and the weakest being 1027.6 $\mathrm{hPa}$. The intensity of most cyclones is between $1000 \mathrm{hPa}$ and $1010 \mathrm{hPa}$ as shown in Figure II, accounting for $42.4 \%$ of all cyclones. There are many cyclones with the center pressure between 900 and $1000 \mathrm{hPa}$, reaching 34.3\%. There is less strong cyclone with a center pressure of less than $990 \mathrm{hPa}$, which accounts for only $9.4 \%$ of the total. The center pressure is less than $980 \mathrm{hPa}$, with an average of 2.3 times per year. The average strength of the spring cyclones in the past years ranged from 998.6 to $1003.9 \mathrm{hPa}$, with no significant increase or decrease, but there are significant interannual variations. From 1961 to 1978 , it was in a relatively strong period, from 1979 to 1999 it was a relatively weak period, and after 2000, it became strong again (Figure III). The average intensity of abnormally strong years is $1963,1969,1971,2001,2004$, and 2013 when the average pressure is less than $1000 \mathrm{hPa}$, and the pressure anomaly is less than $-\sigma$ (standard deviation). The average intensity of abnormally weak years is 1979, 1982, 1984, 1985, 1991, and 1992 when the average pressure is higher than $1002.5 \mathrm{hPa}$, and the pressure anomaly is larger than $\sigma$.
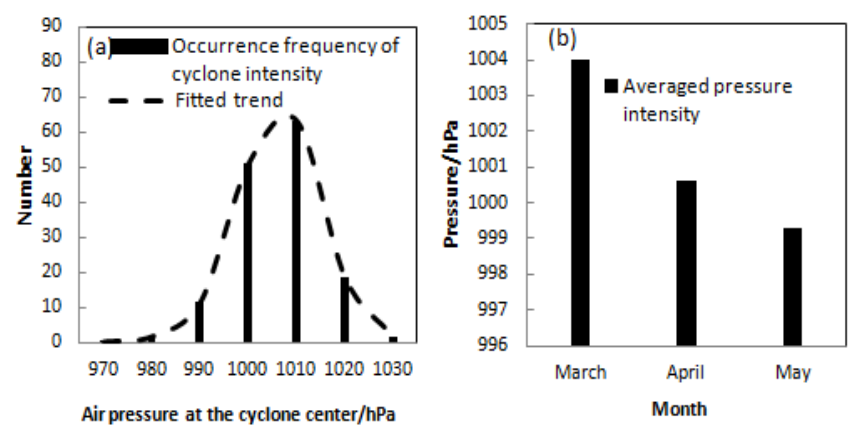

FIGURE II. DISTRIBUTION OF THE CYCLONE OCCURRENCE FREQUENCY IN THE NORTH OF EAST ASIA DURING THE SPRING OF 1961-2016

As for the monthly average intensity, the cyclone was the strongest in May, with an average of $999.2 \mathrm{hPa}$, and it was the weakest in March, with an average of $1003.9 \mathrm{hPa}$. 


\section{INTERDECADAL CHARACTERISTICS OF CYCLONE ACTIVITY IN THE NORTH OF EAST ASIA}

In the spring of 1961-2016, the interdecadal variation of the frequency of cyclone activity in the north of East Asia was significant, and there are significant more active and less active years of the cyclones. From 1961 to 1978, it was a period with more cyclones. Among the 18 years, 15 years are higher than the normal, and only 3 years are lower than the average (Figure III). From 1987 to 2003, it was a period with less cyclones, 19 years in 25 years the frequency of the cyclone activity is less than the average of many years. The number of cyclones began to increase in 2004, and the frequency of cyclone activity of around $70 \%$ of the total years from 2004 to 2016 was higher than the average.

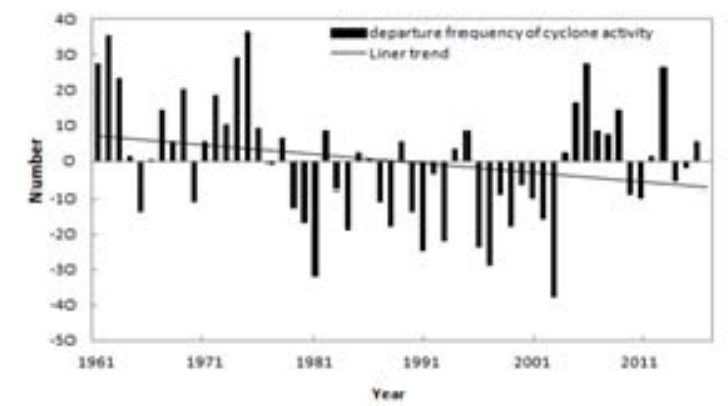

FIGURE III. FREQUENCY ANOMALIES OF CYCLONE ACTIVITIES IN THE NORTH OF EAST ASIA DURING THE SPRING OF 1961-2016

As for the climate trend during the period from 1961 to 2016 (Figure IVa), the occurrence frequency of the cyclones in the north of East Asia showed a decreasing trend, but it was not statistically significant. The occurrence frequency of the cyclones in the north of East Asia from 1961 to 1999 showed a significant decreasing trend (Figure IVb), at a rate of 9 times $/ 10 \mathrm{a}$, the climate trend coefficient is 0.6 , which can pass the significance test of $\alpha=0.01$. The occurrence frequency of East Asian cyclones increased from 2000 to 2016 (Figure IVc) at a rate of 9 times/10a with the climate trend coefficient was 0.3 and passed the statistical significance test of $\alpha=0.05$. Cyclone activity frequency is abnormally high in years of $1961,1962,1974,1975,2006$, and 2013, when its anomaly is larger than one standard deviation $\sigma$. The years of abnormally low cyclone activity frequency were 1981, 1991, 1993, 1996, 1997, and 2003 when its anomaly is smaller than $-\sigma$. Zhi et al. [18] indicated that the winter climate in southern China experienced a sudden change around 1991, and the surface air temperature and extreme rainfall increased significantly after 1991 compared with those before the sudden change. Sein and Zhi [19] investigated the interannual variability of summer monsoon rainfall over Myanmar, and found similar phenomena in different seasons and different regions. This suggested that the interdecadal changes associated with spring cyclones in the north of East Asia are different from those associated with surface temperature and precipitation in tropical regions. The former occurred around a decade later than the latter.
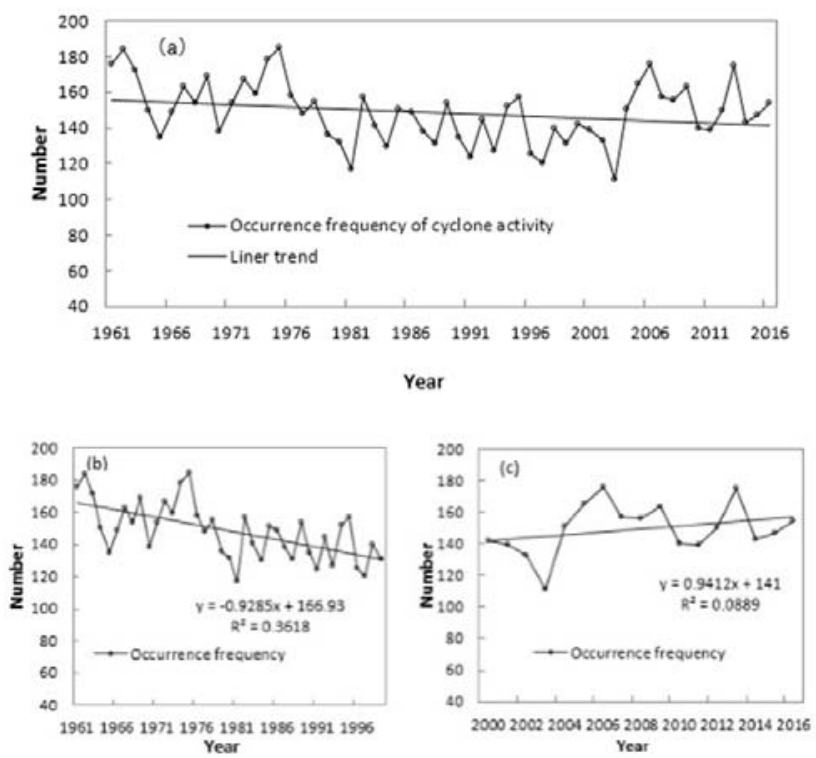

FIGURE IV. INTERDECADAL VARIATIONS AND LINEAR TRENDS OF THE OCCURRENCE FREQUENCY OF CYCLONE ACTIVITIES IN THE NORTH OF EAST ASIA IN SPRING (A: 19612016, B: 1961-1999, C: 2000-2016)

According to monthly data, cyclone activities mostly occurred in May, accounting for $40 \%$ of total spring cyclones, followed by April, accounting for 32\%, and the least in March, accounting for $28 \%$. As shown in Figure V, the Morlet wavelet analysis [20-21] showed that there is a significant period of 2-3 years in the occurrence frequency of cyclones in March, April, and May during the period from 1961 to 2016. As indicated by many authors, there is a significant period of 2-3 years in the precipitation over East China [22-25]. In fact, the quasi-biennial period is also significant in a few of meteorological elements over many other regions [26-28]. This phenomenon was termed the tropospheric biennial oscillation (TBO) [29-30] to distinguish it from the quasibiennial oscillation (QBO) in the stratosphere [31]. In addition, some longer periods of interannual variations were found in the cyclone occurrence frequency over the north of East Asia, and the period became longer from March to May, with the shortest period of around 6 years in March during 1970s, and the longest period of about 10 years in May during around 2000. In April, the period of 8 years is significant in mid1980s. 

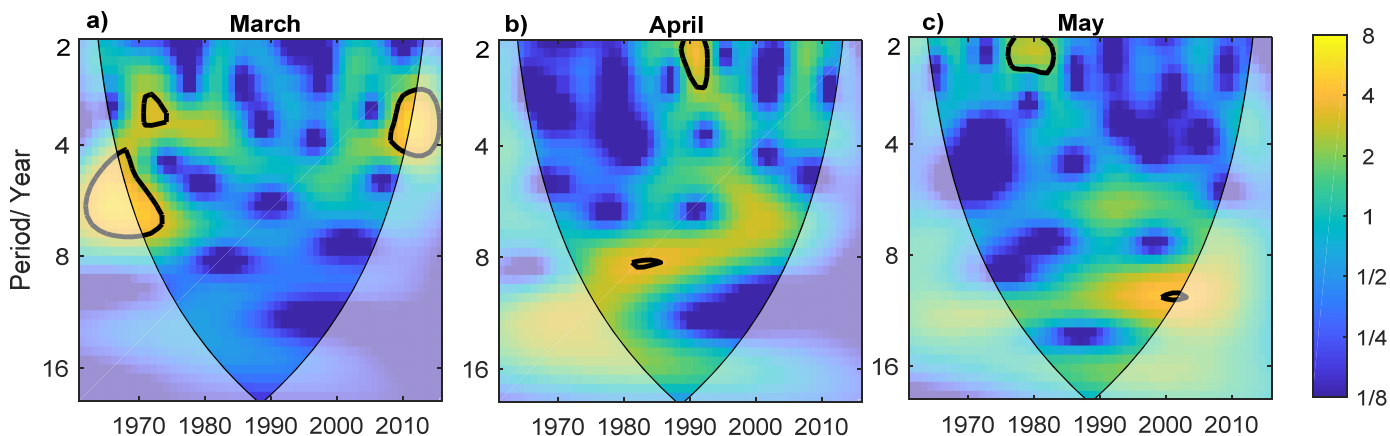

FIGURE V. MORLET WAVELET SPECTRA OF THE CYCLONE OCCURRENCE FREQUENCY IN THE NORTH OF EAST ASIA DURING MARCH (A), APRIL (B), AND MAY(C) FROM 1961-2016. CONE OF INFLUENCE BORDER IS REPRESENTED BY THE THIN CONTOUR, WHILE THE THICK CONTOUR ENCLOSES REGIONS OF GREATER THAN 95\% CONFIDENCE

\section{CONCLUSION AND DiscUSSIONS}

1) There are 4 regions with frequent cyclone activities in the $42.5-52.5^{\circ} \mathrm{N}$ latitudinal zone during boreal spring from 1961 to 2016. One active cyclone center is located in the west of Mongolia and the southeastern Mongolia. Cyclones are also active in the eastern part of the Greater Khingan Range and the Songhuajiang-Nenjiang Plain in Northeast China. In addition, there are two cyclone activity centers which are located in the north of Heilongjiang province and from the east of Inner Mongolia to the west of Jilin province in China, respectively.

2) The interdecadal changes of the occurrence frequency of cyclones in the north of the East Asia were significant, with more cyclones from 1961 to 1978 , less cyclones from 1979 to 2003, and more cyclones from 2004 to 2016. The occurrence frequency of the cyclones in the north of East Asia from 1961 to 1999 showed a significant decreasing trend and a significant increasing trend from 2000 to 2016.

3) Morlet wavelet analysis showed that there is a significant period of 2-3 years in the occurrence frequency of cyclones in March, April, and May during the period from 1961 to 2016. In addition, some longer periods of interannual variations were found in the cyclone occurrence frequency over the north of East Asia, and the period became longer from March to May, with the shortest period of around 6 years in March during 1970s, and the longest period of about 10 years in May during around 2000. In April, the period of 8 years is significant in mid-1980s.

The interdecadal changes of the cyclone activities are significant in the north of East Asia. What's the reason of the climate change in this case? Qian et al. [32] found that in the eastern part of China, the frequencies of dust storms and dust weather in the 1950s-70s were about twice that after the mid1980s. They indicated that the warming in Mongolia and cooling in northern China reduced the meridional temperature gradient, resulting in the reduced cyclone frequency in northern China. Therefore, the reasons of decreasing trend and increasing trend in different decades need to be further investigated by using the composite analysis of the meridional temperature gradients on the background of global warming.

\section{ACKNOWLEDGMENT}

This work was funded by the National Basic Research Program "973" of China (2012CB955204).

\section{REFERENCES}

[1] J. Bjerknes and H. Solherg, "Life cycle of cyclones and polar front theory of atmospheric circulation," Geofys Publikasjoner, Norske Videnskaps-Akad, vol. 3, 1922.

[2] S. Petterssen, "A general survey of factors influencing development at sea leve1," J Meteor, vol.12 (1), 1955, pp.36-42.

[3] B. J. Hoskins, M. E. McIntyre and A. W. Robertson, "On the use and significance of isentropic potential vorticity maps," Quart J Roy Meteor Soc, vol. 111 (470), 1985, pp:877-946.

[4] M. C. Serreze, J. E. Box, R. G. Barry and J. E. Walsh, "Characteristics of Arctic synoptic activity," Meteorol Atmos Phys, vol. 51 (3-4), 1993, pp:147-164.

[5] M. Sick-möller, R. Blender and K. Fraedrich, "Observed winter cyclone tracks in the Northern Hemisphere in reanalysed ECMWF data," Q J R Meteorol Soc, vol. 126, 2000, pp:591-620.

[6] G. J. McCabe, M. P. Clark and M. C. Serreze, "Trends in Northern Hemisphere surface cyclone frequency and intensity," J Clim, vol. 14, 2001, pp:2763-2768.

[7] A. Schneidereit, R. Blender, K. Fraedrich and F. Lunkeit, "Icelandic climate and North Atlantic cyclones in ERA-40 reanalyses," Meteorol Z, vol. 16 (1), 2007, pp:17-23.

[8] X. M. Wang, P. M. Zhai and C. C. Wang, "Variations in extratropical cyclone activity in northern East Asia," Adv Atmos Sci, vol. 26, 2009, pp:471-479.

[9] X. F. Zhi and X. J. Shi, "Interannual variation of blockings in Eurasia and its relation to the flood disaster in the Yangtze River valley during boreal summer, tenth WMO international symposium on meteorological education and training," 2006.

[10] H. Wernli and C. Schwierz, "Surface cyclones in the ERA-40 dataset (1958-2001), part I: Novel identification method and global climatology," J Atmos Sci, vol. 63, 2006, pp:2486-2507.

[11] X. J. Shi and X. F. Zhi, "Statistical characteristics of blockings in Eurasia from 1950 to 2004," Trans Atmos Sci (in Chinese), vol. 30 (3), 2007, pp:338-344.

[12] J. L. Fu, L. Dong and Z. M. Kang, "Climatology and interannual variability of extratropical cyclones in the winter half-year in northern China," Chinese Journal of Atmospheric Sciences (in Chinese), vol. 37 (3), 2013, pp:679-690.

[13] X. Tian and X. F. Zhi, "Climatology of the winter extratropical anticyclones in Eurasia," Acta Meteorol Sin (in Chinese), vol. 74 (6), 2016, pp:850-859. 
[14] X. Tian and X. F. Zhi, "Statistical characteristics of wintertime extratropical anticyclone activity in the Northern Hemisphere," Climatic and Environmental Research (in Chinese), vol. 22 (3), 2017, pp:322-334.

[15] X. F. Zhi, X. Tian, D. Zhu, B. Song and M. Y. Hou, "Interdecadal variations of wintertime anticyclonic activity in the Mongolian Plateau and Iranian Plateau," Chinese J Atmos Sci (in Chinese), vol. 41 (5), 2017, pp:999-1009.

[16] X. D. Ma, X. F. Zhi, J. Wang, J. Chen and H. Z. Feng, "Analysis of the Southwest Vortex Activities in summer and Its Relationship with Precipitation during 1979-2016," Trans Atmos Sci (in Chinese), vol. 41(2), 2018, pp:198-206.

[17] B. J. Hoskins and K. I. Hodges, "New perspectives on the Northern Hemisphere winter storm tracks," J Atmos Sci, vol. 59, 2002, pp:10411061.

[18] X. F. Zhi, L. Zhang and J. L. Pan, "An analysis of the winter extreme precipitation events on the background of climate warming in southern China," J Trop Meteorol, vol. 16, 2010, pp:325-332.

[19] Z. M. M. Sein and X. F. Zhi, "Interannual variability of summer monsoon rainfall over Myanmar," Arab J Geosci, vol. 9 (469), 2016, DOI:10.1007/s12517-016-2502-y

[20] C. Torrence and G. Compo. "A practical guide to wavelet analysis", Bull Amer Meteor Soc, vol. 79, 1998, pp:61-78.

[21] X. F. Zhi, "Interannual variability of the Indian summer monsoon and its modeling with zonally symmetric 2D-Model," Shaker Verlag, Germany. 2001.

[22] Q. G. Zhu and X. F. Zhi, "Quasi-biennial oscillation in rainfall over China," Acta Meteorol Sin, vol. 5(4), 1991, pp:426-434.

[23] X. F. Zhi, "Quasi-biennial oscillation in precipitation and its possible application to long-term prediction of floods and droughts over eastern China," Ann Meteor, vol. 35, 1997, pp:250-252.

[24] H. Yang, X. F. Zhi, J. Gao and Y. Liu, "Variation of East Asian summer monsoon and its relationship with precipitation of China in recent 111 years," Agricultural Science and Technology, vol. 12(11), 2011, pp:1711-1716.

[25] X. Meng and X. F. Zhi, "Interannual and interdecadal variations of drought in Northeast China," Trans Atmos Sci (in Chinese), vol. 39(4), 2016, pp:562-568

[26] D. A. Mooley and B. Parthasarathy, "Fluctuations in All-India summer monsoon rainfall during 1871-1978," Clim Change, vol. 6, 1984, pp:287-301.

[27] S. F. Tian and T. Yasunari. "Time and space structure of interannual variations in summer rainfall over China," J Meteor Soc Jpn, vol. 70, 1992, pp:585-596.

[28] C. P. Chang and T. Li, "A theory of the tropical tropospheric biennial oscillation,” J Atmos Sci, vol. 57, 2000, pp:2209-2224.

[29] G. A. Meehl, "Influence of the land surface in the Asian summer monsoon: external conditions versus internal feedback," J Clim vol.7, 1994, pp:1033-1049.

[30] G. A. Meehl, "The South Asian monsoon and the tropospheric biennial oscillation," J Clim, vol. 10, 1997, pp:1921-1943.

[31] R. Reed, W. J. Cambell, L. A. Rasmusson and D. G. Rogers, "Evidence of a downward propagating annual wind reversal in the equatorial stratosphere," J Geophys Res, vol. 66 (3), 1961, pp:813-818.

[32] W. H. Qian, L. S. Quan and S. Y. Shi, "Variations of the dust storm in China and its climatic control," J Clim, vol. 15, 2002, pp:1216-1229. 